\title{
A insersão da pintura na narrativa
}

Nancy Maria Mendes

Universidade Federal de Minas Gerais

La littérature envie la peinture

(Marcel Proust)

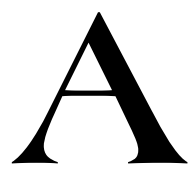

s palavras em epígrafe, ditas pelo romancista francês, referindo-se ao trabalho do escritor, adquirem grande significação se nos lembrarmos do prestígio de que gozou a literatura, durante séculos, na Europa Ocidental, enquanto a pintura era considerada ofício de artesão, só adquirindo status de arte no Renascimento. Seu prestígio entre os literatos passou a ser tal na modernidade, que romancistas de nações diversas a têm inserido em suas obras com certa freqüência e de formas diversas. Mencionarei alguns romances em que isso ocorre, começando por Em busca do tempo perdido, fonte da citação acima. Ali, há numerosas referências à pintura de vários países e épocas, apreciações sobre pintores, descrições e comentários de obras mais ou menos rápidos; não falta um pintor-personagem, a quem são atribuídos quadros ficcionais e quadros reais do acervo de museus, de fácil reconhecimento pelo título e/ou pela descrição; um crítico de arte e marchand figura aí como personagem central de um dos livros. Trata-se de Swann, um duplo do protagonista. Além disso, pode-se observar que figuras de muitas das telas mencionadas se identificam com personagens do livro não só de uma forma mais superficial, pelos traços físicos, como também pelo que simbolizam ou pela situação que vivenciam, indicada pela composição. ${ }^{1} \mathrm{O}$ romancista francês, porém, não foi pioneiro na demonstração de interesse pela pintura. Três décadas antes da publicação de No caminho de Swann, o primeiro livro do romance proustiano, Oscar

${ }^{1}$ Sobre esse assunto, cf. MENDES, 2002. 
Wilde, em O retrato de Dorian Gray (1881), não chegara a atribuir à tela de seu pintor ficcional, Basílio Hallward o poder mágico de preservar a juventude de seu modelo? No romance 1934, obra de caráter filosófico e político, Alberto Moravia leva seu protagonista, um escritor italiano a atribuir à jovem senhora alemã, sua companheira de viagem por quem se apaixona, os sentimentos e conflitos impressos por Dürer na gravura Melancolia, para depois vê-la, estupefato, posando para uma foto do marido como a figura de O Nascimento de Vênus de Botticelli. Duas nações, duas culturas, temáticas opostas, se fazem representar por essas obras evocadas no início da narrativa: a Alemanha e a Itália, a desolação e a vida com o surgimento da amor, da beleza. O protagonista passa por um conflito existencial gerado por situação política que ele recusa (nazismo e fascismo) e agravado pela ambigüidade da mulher que o atrai.

Incluo nesse rol duas obras relativamente recentes da literatura latino-americana: Água viva de Clarice Lispector e O elogio da madrasta de Vargas Llosa. No primeiro, embora satisfeita com sua arte, uma pintora busca na escrita outra dimensão do ser e se deixa seduzir por sua magia. Llosa, aparentemente, se apossa da temática e até da composição de seis telas, cujas reproduções ilustram o livro, para desenvolver sua narrativa erótica.

Enfim, vou deter-me em duas obras de José Saramago, que, de formas diversas entre si e em relação às acima mencionadas, integram o quadro das narrativas literárias que exploram a arte pictural: Manual de pintura e caligrafia (1977) e O conto da ilha desconbecida (1998). O Manual, que antecede o início do sucesso do autor, talvez não seja tão conhecido entre nós quanto outros romances seus. Façamos dele apenas uma leitura preliminar.

No romance, o narrador é um retratista que agrada plenamente seus clientes burgueses, mas não a crítica, que passou a ignorá-lo após tachá-lo de medíocre, nem satisfaz a si mesmo: "Sei muito bem quem sou, um artista de baixa categoria que sabe do seu ofício mas a quem falta gênio, sequer talento". ${ }^{2}$ Nos retratos, melhora o aspecto do modelo, cujo desejo é sempre ser parecido com a figura pintada. A frustração do pintor atinge o limite do insuportável ao tentar, paralelamente ao retrato do empresário S., fazer um outro em segredo. Experimentaria nova forma de expressão e desmascararia o homem que lhe provocava aversão. O segundo retrato

\footnotetext{
2 SARAMAGO, 1992. p. 20.
} 
seria para ele um "certificado de vitória (...), desforra contra a prega irónica que $S$. iria dependurar em suas paredes". ${ }^{3}$ Notando ser incapaz de construir uma obra de arte e de destruir aquele homem com ar de quem "nasceu com todas as batalhas ganhas", ${ }^{4}$ começa a escrever. Estas são as primeiras palavras do romance:

Continuarei a pintar o segundo quadro, mas sei que nunca o acabarei. A tentativa falhou e não há maior prova dessa derrota ou falhaço ou impossibilidade, do que a folha de papel em que começo a escrever: até um dia, cedo ou tarde, andarei do primeiro quadro para o segundo e depois virei a essa escrita, ou saltarei a etapa intermediária, ou interromperei uma palavra para ir pôr uma pincelada na tela do retrato que $S$. encomendou ou naquele outro paralelo que S. não verá. ${ }^{5}$

Uma personagem com a condição de pintor que experimenta a literatura tem precedente em Água viva, mas bem diversas são agora as circunstâncias. A palavra caligrafia no título parece-me boa estratégia. O trabalho de calígrafo convém à personagem, que poderá explorar sua habilidade de pintor, ao copiar textos. Em algumas passagens, descreve sua tarefa:

Quando assento o aparo na curva interrompida de uma letra, de uma palavra, de uma frase, quando prossigo dois milímetros adiante de um ponto final ou de uma vírgula, limito-me a prosseguir um movimento que vem de trás: este desenho é ao mesmo tempo o código e a decifração. ${ }^{6}$

Em outro ponto, ele diz estar copiando textos literários "para adestrar a mão como se estivesse a copiar um quadro". ${ }^{7}$ Coabitam nessas palavras a metáfora e o sentido literal, pois há o desenho do manuscrito

Que textos literários mereceriam maior atenção de um retratista que os de caráter biográfico? Os primeiros trechos são o início de duas obras ficcionais: Robson Crusoé de Daniel Defoe e Memórias de Adriano de M. Yourcelar; e de uma não ficcional - Confissões de Rousseau.

${ }^{3}$ SARAMAGO, 1992. p. 11.

${ }^{4}$ SARAMAGO, 1992. p.17.

5 SARAMAGO, 1992. p. 5.

${ }^{6}$ SARAMAGO, 1992. p. 61.

7 SARAMAGO, 1992. p. 94. 
Diante desses exemplos, estou eu, H., incógnito nessa inicial, enquanto escolarmente copio e tento perceber, inclinado a afirmar que toda a verdade é ficção, abonando-me para o dizer, em seis testemunhos de verdade suspeita e de mentira idônea que são Robson e Defoe, Adriano e Youcelar e Rousseau duas vezes. ${ }^{8}$

Como boa parte do que escreve caracteriza-se como diário (contra seu próprio desejo), outros textos vão sendo copiados, de acordo com sua preocupação no momento. É o caso de um trecho da Contribuição para a Crítica da Economia Política de Marx (p.195-197), quando pretende ampliar reflexões, que passaram pela arte e pela filosofia socrática. Definese assim sua posição política. O Decreto de Restauração da Inquisição na Espanha de Fernando VII, em 1808 (p. 227-8), vem após referir-se a obras de Goya, que registram acontecimentos dele decorrentes. H. justifica a inclusão desse texto: "a fim de também alguma parte ficar explicada de Portugal, não parecendo"... É a revolta contra a ditadura! É o início de uma nova fase de vida e a pintura continua presente.

Lembremos que não há meras referências à cópia desses textos e a seu conteúdo, mas sua insersão material no do narrador. Assim sendo, ocorre aí outra técnica de pintura - a colagem - não indicada pelo autor. Convém ressaltar que, os trechos não literários, que interessam pelas idéias que veiculam, vêm limitados pelas aspas usuais, como uma colagem delimitada, por um contorno, por exemplo; os literários se inserem livremente no texto, apenas com identificação da procedência, talvez por serem modelos formais em experiência. Neste último caso, equivaleria a uma colagem cujos limites não são postos em evidência, embora não sejam ocultados. Quem escreve é um pintor que, na verdade, não pretendeu emigrar para outra arte:

Recorrendo à escrita, sabia que simplesmente virava costas a uma dificuldade: não a ignorava, sabia-a do mesmo modo ameaçadora, mas era como se a novidade do instrumento, tudo quanto para mim tinha de ser real invenção e não mero decalque de experiências anteriores bastasse por si para me aproximar do objetivo. ${ }^{10}$

\footnotetext{
${ }^{8}$ SARAMAGO, 1992. p. 96.

${ }^{9}$ SARAMAGO, 1992. p. 227

${ }^{10}$ SARAMAGO, 1992. p. 77.
} 
Seus cinco "exercício[s] de autobiografia em forma de capítulo[s] de livro", que se intercalam ao registro de fatos do presente, uns poucos do passado e muitas reflexões sobre a arte e a vida, constituem relatos de viagem à Itália, cujo centro de interesse são as visitas a museus e igrejas para ver quadros, que relaciona, descreve ou comenta. Longa é a relação de pintores e obras das onze cidades por onde passou. Penso que uma análise desses elementos poderia definir o ideal estético do retratista. O significado da pintura para ele se exprime no "segundo exercício", assim anunciado: "Título: Eu, bienal em Veneza"...

O refúgio que o protagonista buscou na escrita, iria auxíliá-lo, pela reflexão, a descobrir-se separado de S., dos novos clientes, e de si mesmo. Tinha chegado a essa conclusão: "não gosto de mim e sou obrigado a verme em cada retrato que pinto, inútil, cansado, desistente, perdido, porque não sou Rembrandt nem Van Gogh". ${ }^{11}$ Constata-se, então, ser o exercício da escrita apresentado, tacitamente, por Saramago como uma terapia eficaz, que recupera o artista e o homem. À medida que ela avança $\mathrm{H}$. vaise transformando: enfrenta e afronta os clientes burgueses, libera a capacidade criativa, pintando de forma independente e prazerosa; assume atitudes políticas e inicia uma promissora relação amorosa baseada em respeito e admiração mútuos. É a cura pela palavra, mas nesse caso, sem os ouvidos testemunhais do psicanalista... A personagem teve consciência da evolução do processo e a tem do resultado:

Há coisas que começam agora a tornar-se claras, diria mesmo que já me parecem óbvias, quando antigamente eram caos e confusão, eram outra forma de labirinto, sem dúvida redutível à linha recta, mas que complica essa redutibilidade, enovelando-se e apertando-se sobre si próprio ou comprimindo os espaços, por onde a circulação se faz. ${ }^{12}$

Esse projeto de autobiografia por caminhos que quiseram ser diferentes, juntando em partes iguais artifício e verdade, que foi que dele saiu? Que edifício? Que ponte? Que resistência de que material? Responderia que me aproximei. Responderia que ajustei o corpo e a sua sombra, que apertei o parafuso solto. ${ }^{13}$

\footnotetext{
${ }^{11}$ SARAMAGO, 1992. p.

12 SARAMAGO, 1992. p. 194.

${ }^{13}$ SARAMAGO, 1992. p. 221.
} 
Ao longo do livro, a invenção de uma personagem que, sendo pintor, passa a escrever, de um "escrepintor", segundo ele, permite a Saramago, observações quanto à relação e à correspondência entre as duas artes que não se desenvolvem muito, às vezes parecem ingênuas, às vezes são poéticas, mas de alguma forma interessantes. Para H., não são acentuadas "as diferenças entre palavras que às vezes são tintas e as tintas que não conseguem ser palavras"; misturar as tintas na paleta corresponde a brincar com as palavras; "o substantivo é o traço e o verbo, a côr"; "escrever é uma escolha, tal como pintar. Escolhem-se, partes de diálogos, como se escolhem cores ou se determina a extensão e a direcção das linhas"14 (p. 263). A grande interseção que percebe entre essas artes é que, em ambas, "tudo é biografia" e essa afirmativa é feita reiteradamente. Assim, o retratista descobriu-se no exercício da escrita.

Diga-se de passagem, que não se pode deixar de observar ter Saramago emprestado à sua personagem uma percepção das questões literárias que vai além das possibilidades de quem teve sempre a atenção voltada para a pintura, de quem não teria conhecimentos teóricos de literatura e estava apenas começando a escrever. Estão nesse caso, sua desenvoltura na comparação entre biografia ficcional e não ficcional; sua compreensão do desdobramento do eu do narrador de primeira pessoa em aquele que narra e quem é objeto da narrativa; considerações sobre as vantagens e desvantagens da narrativa em primeira pessoa - "Escrever em primeira pessoa é uma facilidade, mas é também uma amputação", ${ }^{15}$ comenta ele. Nota-se nitidamente, nesses momentos, a voz experiente do autor do romance falando por trás da escrita da personagem.

Acredito que o leitor não se surpreenderia, se a personagem não voltasse a seu antiga atividade e se tornasse de vez um escritor, pois descobrira "arte doutra maior sutileza". A ambigüidade, porém, perturbao e leva-o de volta à sua arte, com o projeto do auto-retrato.

Bem diversa e não menos significativa é a presença da pintura no pequeno volume O conto da ilha desconhecida.

Saramago constrói aí uma espécie de conto popular com situações sócio-políticas exemplares e muita poesia. O súdito sonhador vence, pela ousadia e persistência, a prepotência e insensibilidade do rei para ganhar

\footnotetext{
${ }^{14}$ SARAMAGO, 1992. p. 263.

15 SARAMAGO, 1992. p. 113.
} 
o barco desejado, aliás, recebe uma velha caravela. Seu sonho, absurdo como costumam ser os sonhos, de ir buscar a ilha desconhecida sem ser nem ter marinheiro não será frustrado, graças ao equilíbrio entre a fantasia e a realidade que lhe propicia a mulher da limpeza do palácio real, ela, que deixara seu trabalho enfadonho naquela casa de muitas portas, pela "porta das decisões", para acompanhar o homem e o sonho. Quando ele percebe a inviabilidade da viagem, ela já estava embarcada... Passaram a primeira noite no barco, cada um ecolheu seu beliche, mas ele acordou de um sonho em que estava viajando, "abraçado à mulher da limpeza e ela a ele, confundidos os corpos, confundidos os beliches". ${ }^{16}$ Depois, mal nasceu o sol, foram os dois pintar o nome da caravela. "Pela hora do meiodia, com a maré, A Ilha Desconhecida, fez-se enfim ao mar, à procura de si mesma." 17

De referência à pintura, não há outra no texto além dessa do nome do barco em tinta branca na proa, de um e de outro lado. E não seria, talvez, pouca coisa, desde que pensemos na magia das palavras pintadas que permitem a viagem do homem e da mulher, sem saírem do porto... Mas a pintura tem nesse livro uma presença material (ou virtual?) pelas ilustrações. São reproduções de dez aquarelas de Arthur Luiz Piza. Três delas, ao se aproximarem do figurativo nos sugerem a possibilidade de a série ter sido feita expressamente para o conto. A primeira se encontra na capa, representa um barco e um pequeno quadrilátero irregular, distante dele, sugerindo a ilha; a segunda, um retângulo em posição vertical, poderia corresponder à "porta das petições"; na última, a imagem do barco de outro modo se recompõe, integrando, pelo que percebo, a figura da ilha, em outra côr e dimensão maior. Nas outras, impera o abstracionismo.

Reflitamos sobre a opção de Saramago por ilustrar esse pequeno volume, buscando a colaboração do aquarelista Arthur Luiz Piza. Evidentemente isso vai muito além de confirmar seu interesse pela pintura. Abrindo-lhe espaço, leva-nos a pensar que conceba uma relação de complementaridade entre as duas artes. As formas geométricas bicolores, tricolores ou em dégradé, sobre um fundo em tom pastel, são geralmente retangulares, assemelhando-se a folhas ou placas finas de dimensões, disposições variadas. Às vezes se sobrepõem como que estivessem caindo

\footnotetext{
${ }^{16}$ SARAMAGO, 1998. p. 62.

${ }^{17}$ SARAMAGO, 1998. p. 62.
} 
ou sendo atiradas contra o fundo; um pequeno triângulo pode interferir, parecendo ser fragmento de uma das figuras cuja côr repete. Em algumas das ilustrações, outros quadriláteros se sobrepõem ou interferem; aliás, na própria superposição dos retângulos, claramente sugerida, outras figuras se formam. Linhas curvas só aparecem nas duas representações do barco e no desenho esboçado no fundo de uma das ilustrações. É inegável o caráter lúdico dessas composições. Eu ousaria dizer que nelas predomina uma harmoniosa desordem, como nos nossos anseios, talvez... O elemento visual por elas acrescentado à obra, acentua a poesia do texto.

Se no Manual de escritura e caligrafia a arte pictural está presente pela palavra atribuída ao pintor-narrador, no Conto da ilha desconbecida, ela ganha, concretude pela reprodução das aquarelas destituídas de títulos e de legendas. O pintor nessa narrativa ficcional de Saramago deixou de ser uma personagem, passando a um parceiro do escritor, a co-autor do livro.

\section{Referências Bibliográficas}

LISPECTOR, Clarice. Água viva. Rio de Janeiro: Nova Fronteira, 1980.

LLOSA, Mario Vargas. El elogio de la madrastra. Barcelona, 1988.

MENDES, Nancy Maria. Uma galeria de pintores holandeses no romance proustiano. São Paulo: Annablume, 2002.

MORAVIA, Alberto. 1934. Trad. Udine Tausz de Macedo. Rio de Janeiro: Nova Fronteira, 1985.

PROUST, Marcel. Em busca do tempo perdido. Trad. Mário Quintana et alli. Porto Alegre: Ed. Globo, 1948, 1951, 1954, 1956, 1957.

SARAMAgO, José. Conto da ilha desconhecida. Aquarelas de Arthur Luiz Piza. São Paulo: Companhia das Letras, 1998.

SARAMAgO, José. Manual de escritura e caligrafia. São Paulo: Companhia das Letras, 1992.

WILDE, Oscar. O retrato de Dorian Gray. Trad. Oscar Mendes. S. Paulo: Abril Cultural, 1981. 


\section{Resumo}

Trata-se, neste trabalho, da presença da pintura em narrativas literárias modernas e das diferentes formas de elas aí se instalarem. Dois livros de José Saramago são particularmente focalizados: Manual de pintura $e$ caligrafia e O conto da ilha desconbecida. É analisado discurso do protagonista do primeiro, um artista na tentativa de deixar a pintura pela literatura. Em relação ao segundo, são tecidas considerações sobre a função da pintura inserida no livro concretamente pelas ilustrações e do pintor, não mais personagem, mas co-autor do livro.

\section{Résumé}

On parle, dans ce travail, de la présence de la peinture dans des récits littéraires modernes et de différentes possibilités de s'y installer. Deux livres de José Saramago - Manual de pintura e caligrafia et O conto da ilha desconhecida reçoivent une attention spéciale. On analyse le discours du protagoniste de la première ouvre, un artiste entre les deux arts, un portraitiste qui s'initie à la littérature; par rapport à la deuxième, on considère une autre fonction du peintre non plus un personnage, mais le coauteur du livre, dont les illustrations sont un complément du texte. 